\title{
RNAi-Based Biofungicides as a Promising Next-Generation Strategy for Controlling Devastating Gray Mold Diseases
}

\author{
Md Tabibul Islam and Sherif M. Sherif* \\ Alson H. Smith Jr. Agricultural Research and Extension Center, School of Plant and Environmental Sciences, \\ Virginia Tech, Winchester, VA 22602, USA; tabibul@vt.edu \\ * Correspondence: ssherif@vt.edu; Tel.: +1-540-232-6035
}

Received: 12 February 2020; Accepted: 16 March 2020; Published: 18 March 2020

\begin{abstract}
Botrytis cinerea is one of the most critical agro-economic phytopathogens and has been reported to cause gray mold disease in more than 1000 plant species. Meanwhile, small interfering RNA (siRNA), which induce RNA interference (RNAi), are involved in both host immunity and pathogen virulence. B. cinerea has been reported to use both siRNA effectors and host RNAi machinery to facilitate the progression of gray mold in host species. Accordingly, RNAi-based biofungicides that use double-stranded RNA (dsRNA) to target essential fungal genes are considered an emerging approach for controlling devastating gray mold diseases. Furthermore, spray-induced gene silencing (SIGS), in which the foliar application of dsRNA is used to silence the pathogen virulence genes, holds great potential as an alternative to host-induced gene silencing (HIGS). Recently, SIGS approaches have attracted research interest, owing to their ability to mitigate both pre- and post-harvest $B$. cinerea infections. The RNAi-mediated regulation of host immunity and susceptibility in B. cinerea-host interactions are summarized in this review, along with the limitations of the current knowledge of RNAi-based biofungicides, especially regarding SIGS approaches for controlling gray mold diseases under field conditions.
\end{abstract}

Keywords: Botrytis cinerea; spray-induced gene silencing; RNAi-based biofungicide; siRNA; dsRNA

\section{Introduction}

Botrytis cinerea has been reported to cause gray mold disease in more than 1000 plant species, including many fruits and leafy vegetables, thereby causing huge annual economic losses (more than $\$ 10$ billion) worldwide [1]. Due to its wide host range and economic impact, $B$. cinerea is considered as the second most agro-economically important plant pathogen after Magnaporthe oryzae [2]. Botrytis cinerea is generally considered as a necrotroph, which uses a diverse array of lytic enzymes and phytotoxins to damage or destroy host cells in order to acquire nutrients [1]. However, it has recently been shown that a short biotrophic phase (during $8-16 \mathrm{~h}$ post-inoculation) may play a crucial role in the pathogenesis of $B$. cinerea $[3,4]$. Hence, it may be more reasonable to classify $B$. cinerea as a hemibiotrophic phytopathogen [4] and to more thoroughly investigate the early infection stage of this pathogen to develop more effective management strategies.

Integrative approaches that incorporate good agronomic and horticultural practices are typically used along with chemical fungicides to control gray mold diseases [1]. Without the application of synthetic fungicides, crop losses to gray mold at pre- and post-harvest stages can reach $40 \%$ [5,6]. However, extensive uses of chemical fungicides have often been associated with severe consequences on human health and the ecosystem, urging the need for safer and eco-friendly alternatives [7-9]. Additionally, some fungicides (e.g., quinone outside inhibitor (QoI) class fungicides, such as azoxystrobin or trifloxystrobin) 
used against gray mold are no longer effective due to the emergence of resistant $B$. cinerea strains $[10,11]$. To overcome these issues, biotechnological approaches using genetic engineering have extensively been employed to control gray mold diseases. Host-induced gene silencing (HIGS) is one of the methods that have been used to enhance resistance against $B$. cinerea, by expressing dsRNAs that target essential fungal genes in host plant species leading to disease resistance [12,13]. For instance, Arabidopsis plants expressing hairpin RNA (hpRNA) targeting Dicer-like genes of B. cinerea [14] and transgenic potato and tomato plants expressing the dsRNA that is complementary to the target of the rapamycin (TOR) gene of $B$. cinerea, strongly reduced the gray mold occurrence in these host plants [15]. The HIGS can achieve durable resistance; however, due to the lack of a stable genetic transformations system for several economically important crops, the costs associated with development, registration, and maintenance of the genetically modified crops, as well as the challenges related to the public acceptance of these plants, utilization of HIGS as a disease management strategy against $B$. cinerea is not currently attainable.

Recently, the exogenous application of double-stranded RNA (dsRNA-), small interfering RNA (siRNA-), and hpRNA-mediated post-transcriptional gene silencing (i.e., RNA interference or gene silencing) has emerged as a promising strategy in enhancing plant resistance against phytopathogenic diseases [16]. For instance, topical applications of dsRNAs or siRNAs that target genes involved in the ergosterol biosynthesis in Fusarium graminearum (CYP51A, CYP51B, and CYP51C), suppressed the fungal growth in barley [17]. Similarly, spraying wheat plants with the dsRNA targeting myosine 5 gene of $F$. asiaticum reduced fungal virulence [18]. In Brassica napus, exogenous applications of dsRNAs targeting various genes of $B$. cinerea also decreased the gray mold disease severity [19]. The dsRNAs or siRNAs targeting the B. cinereal siRNA biosynthesis-related genes, such as Dicer-like 1 and 2 (DCL1 and DCL2), significantly reduced the gray mold diseases in various fruits and vegetables [14].

Crop losses due to $B$. cinerea during cultivation and post-harvest handling entail more specific and efficient management strategies against this phytopathogen. RNAi-based fungicides have attracted great interest for controlling fungal diseases, owing to their greater specificity and efficiency. This review aims to summarize recent observations and findings regarding the use of RNAi-based fungicides for controlling gray mold diseases, including the putative modes of action, applications, and limitations, especially in regard to the implementation of RNAi-based approaches for controlling gray mold diseases in the field.

\section{RNAi: Biosynthesis and Actions}

The biogenesis of siRNA is achieved by synthesizing dsRNA [20] from single-stranded RNA (ssRNA) templates using RNA-dependent RNA polymerase (RDR). RDR cleaves the dsRNA into small (mostly 20-30 nucleotides long) interfering RNA (siRNA) using Dicer endoribonucleases or Dicer-like (DCL) proteins [21], combining one strand of the siRNA (i.e., single-strand, or guide siRNA) and Argonaute (AGO) proteins to form RNA-induced silencing complexes (RISCs). The second strand (also known as the passenger strand) of the double-stranded siRNA is then degraded. The resulting RISC targets messenger RNA (mRNA) molecules that are complementary to the siRNA and degrades them, thereby inducing gene silencing (i.e., RNAi) [22].

The RNAi-based gene-silencing pathway has great diversifications in terms of its functionality. For instance, four homologs of DCL (DCL1, DCL2, DCL3, and DCL4) have been found in Arabidopsis; among these, DCL1 mainly cleaves the dsRNA and synthesizes the 18-21-nucleotides (nt), whereas DCL2, DCL3, and DCL4 synthesize the 22-, 24-, and 21-nt siRNA, respectively [23,24]. All these forms of siRNA play different roles in the plant. For instance, the siRNA 21-nt incorporates with AGO1 for the degradation of complementary mRNA sequences in a process collectively known as post-transcriptional gene silencing. However, when AGO1 is loaded with the siRNA 22-nt, it recruits RDR6 and transcribes it into dsRNA to activate secondary siRNA synthesis. The 24-nt siRNA, on the other hand, forms a complex with AGO4 and activates RNA-directed DNA methylation by using the DNA methyltransferase [25]. 


\section{Small Interfering RNA (siRNA) Regulate the Virulence of B. cinerea}

The world's second most destructive phytopathogen, B. cinerea, employs a variety of virulence factors, including siRNA, to induce host susceptibility [21]. Such siRNA effectors play significant roles in the early stage of $B$. cinerea infection, as well as in the progression of gray mold diseases in a variety of crops and fruits [26]. B. cinerea uses siRNA effectors to manipulate the innate immunity of plant hosts by suppressing host defense responses (e.g., programmed cell death) to facilitate asymptomatic colonization (i.e., biotrophic phase), which occurs before the destructive necrotrophic phase. Previous studies have reported that $B$. cinerea DCL1 and DCL2 proteins synthesize and deliver siRNA to host plant cells to interfere with the host RNAi machinery of AGO1 and subsequently silences and suppresses the immune response of the host species [3]. The detailed characterization and profiling of the B. cinerea siRNA in infected plant tissue revealed that the Bc-siR3.2, Bc-siR5, and Bc-siR3.1 can target a variety of plant defense regulating factors, including genes for mitogen-activated protein kinases (e.g., MPK1, MPK2, and MAPKKK4), cell wall-associated kinase (e.g., WAK), and peroxiredoxin (e.g., $P R X I I F)$, respectively [3] (Figure 1).

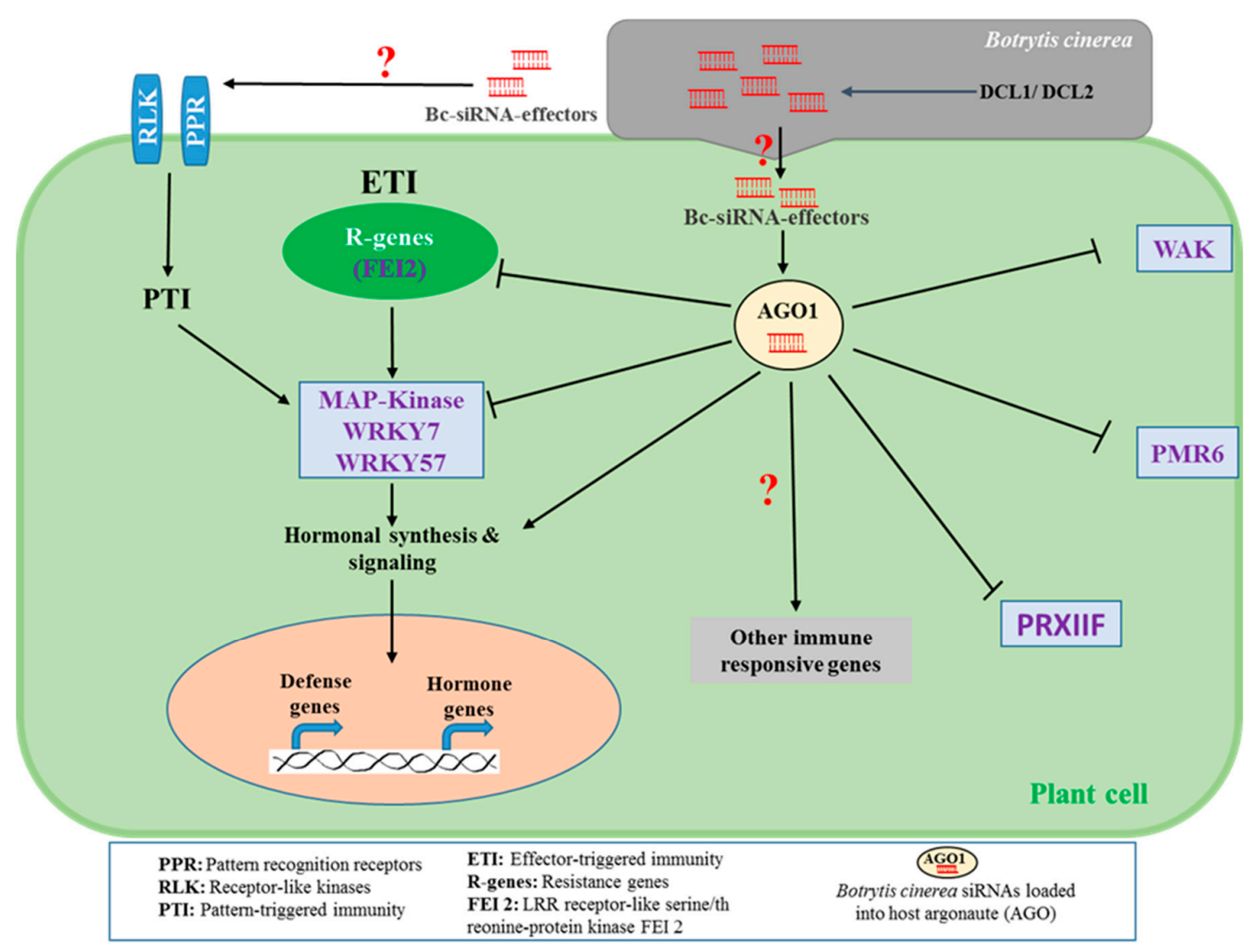

Figure 1. Botrytis cinerea's small RNA (sRNA) effectors modulate the plant immune system to induce the gray mold disease. B. cinerea synthesize small interfering RNA (siRNA) effectors by Dicer-like 1 and 2 proteins (DCL1 and DCL2) and deliver them to host plant cells to interfere with the host RNAi machinery (argonaute; AGO1) and subsequently silence and suppress the plant defensive factors, including leucin rich repeat (LRR) receptor-like serine/threonine-protein kinase FEI 2, mitogen-activated protein kinases (MAP-kinase), WRKY7, WRKY57, cell wall-associated kinase (e.g., WAK), pectinlyase (e.g., PMR6), and peroxiredoxin (e.g., PRXIIF). The mechanisms by which $B c$-siRNA interfere with the plant immunity systems (e.g., PTI and ETI), hormonal biosynthesis and signaling as well as immune responsive genes have been perceived but are not fully understood.

These genes play a central role in plant defense signaling pathways. For instance, mitogen-activated protein kinases (MPKs) are known to regulate hormone biosynthesis and signaling [27], thus activating 
the plant defenses against biotrophic [28], hemibiotrophic [29], and necrotrophic pathogens [30]. On the other hand, peroxiredoxin is one of the redoxins found in plant cells that regulates redox homeostasis (glutathione, ascorbate, NADPH-dependent redox), a process that has been linked to innate [31] and inducible immunity [32]. As far as the resistance to B. cinerea is concerned, the enhancement of glutathione- and ascorbate-dependent redox status is the prime defense responses in tomato against $B$. cinerea [32]. Bc-siRNA suppresses peroxiredoxin to manipulate the redox balance, hence increasing tissue susceptibility to $B$. cinerea infections [3]. Another virulence strategy that $B$. cinerea employs is the secretion of endopolygalacturonase that is involved in the degradation of host cell-wall pectins, releasing oligogalacturonides (OGs) [33]. The OGs are recognized as pathogen-associated molecular patterns (PAMPs) by the plant wall-associated kinase 1 (WAK1) and trigger a diverse array of plant defense responses, including enhanced camalexin biosynthesis [34,35]. To manipulate the cell wall-mediated defensive factors, B. cinerea produces siRNA that target WAK genes for silencing [14]. However, the detailed underlying mechanism of the RNAi-mediated regulations of cell wall-dependent defense remains largely unexplored.

Most of the predicted $B c$-siRNA effectors are derived from retrotransposon regions [3]. However, Wang et al. [36] characterized an siRNA effector of $B$. cinerea, $B c$-siR37 that is derived from a gene encoding a Bc-ATPase and that targets several immune responsive factors including the WRKY7, WRKY57, PMR6, and FE12 in Arabidopsis (Figure 1). Among them, FEI2 is a leucine-rich repeat (LRR) receptor kinase which is a plant immune-related transcriptional factor involved in effector-triggered immunity. PMR6 encodes a pectinlyase and this, along with FEI2, are involved in the defense responses against $B$. cinerea [36]. On the other hand, the transcriptional factor WRKY7 is known as a negative regulator of the salicylic acid (SA)-dependent $P R 1$ gene activation [37], and WRKY57 is another transcriptional factor that binds to the JASMONATE ZIM-domain 4/8 (JAZ4/8) and activates the jasmonic acid (JA)-responsive defense genes [38]. Given the known role that JA plays in resistance against necrotrophic pathogens, along with the antagonistic relationships between SA- and JA-dependent defense pathways [31], it could be thus suggested that B. cinereal siRNA effector Bc-siR37 simultaneously silences the negative regulator of SA signaling to induce SA-JA antagonism and hence inactivates JA-mediated defenses against B. cinerea.

\section{Plant siRNA Induce Immune Responses to Counteract B. cinerea Infections}

siRNA and microRNA (miRNA) regulate a variety of cellular processes, including plant immunity [39]. RNA-dependent RNA polymerases (RDRs or RdRPs) are involved in the biosynthesis of dsRNA, which function as precursors for siRNA during siRNA synthesis [20]. Interestingly, Arabidopsis loss of function mutants $r d r 6, d c l 1-7$, and $d c l 2 / 3 / 4$ show greater susceptibility to gray mold $[3,40]$, demonstrating the role of RNAi in defense against $B$. cinerea. On the other hand, Cai et al. [41] recently reported that Arabidopsis secretes extracellular vesicles, especially tetraspanin 8 (TET8)-associated exosomes that are loaded with plant siRNA (e.g., ta1c-siR483, ta2-siR453) in order to silence virulence genes in B. cinerea (Figure 2). Among fungal genes that are targeted for silencing are vas51, dctn1, and sac1, the three vesical trafficking genes associated with fungal pathogenicity [41]. Despite the significance of these results, the mechanisms underlying the loading of siRNA into vesicles and the transport of those vesicles into fungal cells remain largely unknown. More thorough research to understand the role of the vesical trafficking system in B. cinerea-host interactions could lead to the identification of important targets for RNAi-based fungicides and, more importantly, the discovery of effective methods for siRNA delivery to fungal cells.

Plant defense against invading pathogens relies on two forms of resistance-PAMP-triggered immunity (PTI) and effector-triggered immunity (ETI). Plant pathogens secrete effectors to suppress and interfere with both types of plant defenses. On the other hand, plants have evolved resistance genes (R-genes) and proteins (R-proteins) to directly or indirectly interact with and hinder the action of effector proteins, and subsequently activate the plant ETI responses [42]. Although most effectors are proteins, it was recently reported that $B$. cinerea employs siRNA effectors to suppress plant defenses 
via the host RNAi system [3]. The functional characterization of the RNAi-mediated regulation of hormonal signaling that regulates downstream defense responses [43] is necessary to fully understand in B. cinerea-host interactions.

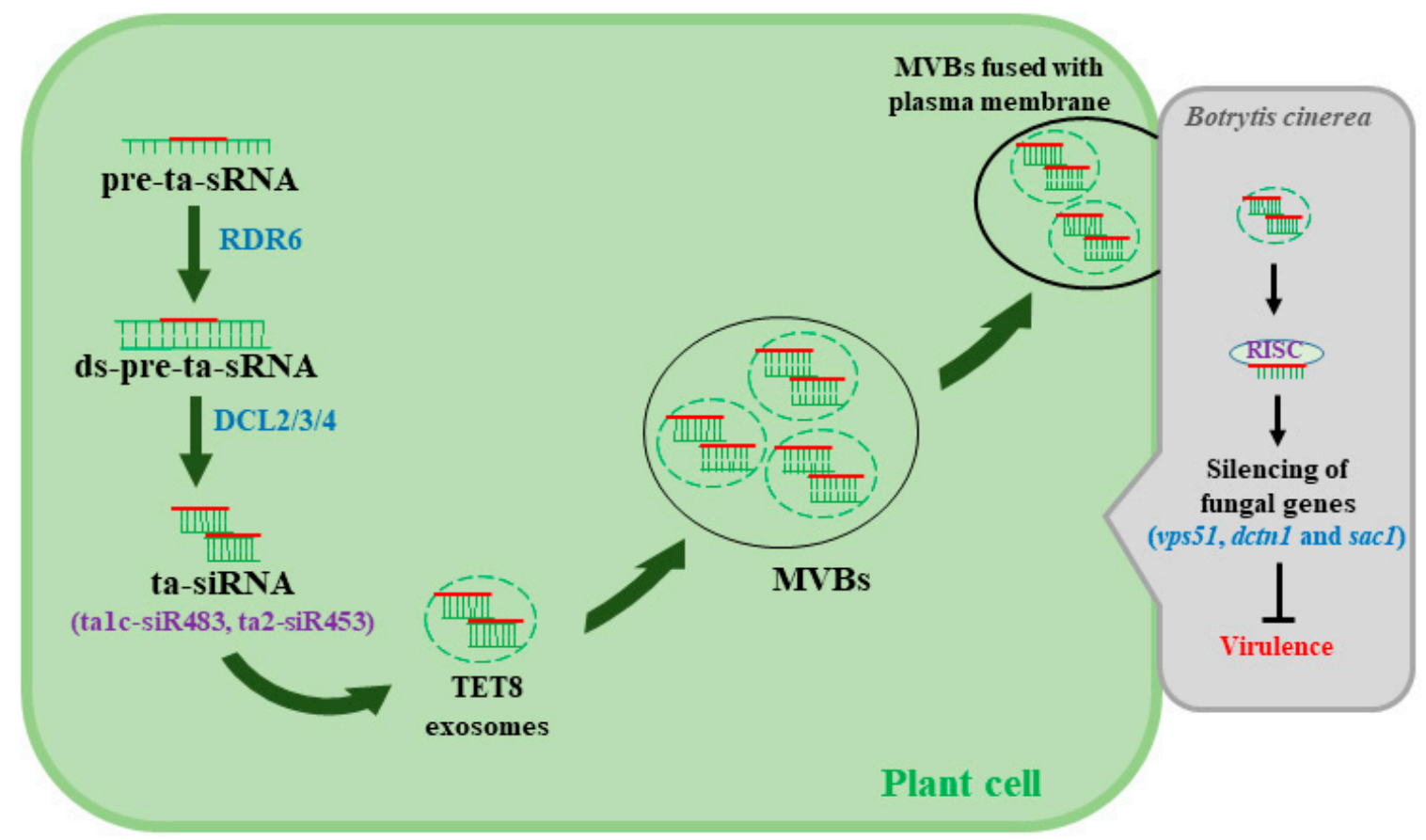

Figure 2. Plant delivers extracellular vesicles (EVs) containing siRNA to fungal cells to counteract Botrytis cinerea. Trans-acting siRNA (ta-siRNA) is processed by RNA-dependent RNA polymerase 6 (RDR6) and DCL2/3/4, and the processed ta-siRNA translocate through an unknown mechanism to tetraspanin 8 (TET8)-associated exosomes that are then assembled to form multivesicular bodies (MVBs). MVBs are fused with the plant plasma membrane to facilitate the transfer of siRNA to the invading fungal cells. The mechanisms behind the selection process of siRNA that translocate to the EVs and the release of siRNA into fungal cells to silence target virulence genes remain largely unknown.

\section{RNAi-Based Biofungicides and Spray-Induced Gene Silencing (SIGS) for Controlling B. cinerea}

Chemical fungicides are mostly used to control fungal diseases, including the gray mold diseases caused by B. cinerea. Fungicides with different modes of action are used against $B$. cinerea, including QoIs (e.g., anilinopyrimidines, dicarboximides, hydroxyanilides), succinate dehydrogenase inhibitors (e.g., boscalid, fluopyram), phenylpyrroles (e.g., fludioxonil), and hydroxyanilides (e.g., fenhexamid) $[10,11,44,45]$. Although synthetic fungicides offer an effective means of crop protection, there are many detrimental effects on human and plant health due to fungicide usage. The application of chemical fungicides impairs the plant's metabolic and physiological pathways, such as photosynthesis, $\mathrm{CO}_{2}$ assimilation, reproductive organ development, and nitrogen, and carbon metabolism, and it may cause plant growth reduction and phytotoxicity $[46,47]$. Additionally, the extensive use of fungicides generates long-term residues in food and the environment. Some fungicides are also known to disrupt the human endocrine system and may cause abnormalities in the reproductive system [48]. A competitive alternative to synthetic fungicides would drastically reduce the indirect economic costs that fungicide usage inflicts on society. Moreover, multiple fungicide-resistant Botrytis strains have also been reported [10], especially in strawberry [49], raspberry [50], grape [51], and tomato [52]. Furthermore, the adverse effects of chemical fungicides on the environment and the lower efficacy of chemical fungicides against B. cinerea have been reported [1]. By reducing the use of synthetic fungicides and, therefore, the off-target exposure of fungicides to humans, non-target organisms, agricultural soils, and freshwater resources, billions of dollars can be saved each year. Therefore, new eco-friendly approaches should be implemented in the management of $B$. cinerea. The use of 
RNAi-based fungicides represents a promising alternative that could both control gray mold diseases and overcome the adverse effects of current strategies. Spray-induced gene silencing (SIGS) is an innovative RNAi-based approach for silencing target genes in phytopathogens using exogenous applications (Figure 3). The exogenous application of dsRNA and siRNA has been reported to reduce B. cinerea infection in strawberry and tomato fruits as well as detached leaves of oilseed rape $[14,53]$, thereby initiating a new era of RNAi-based fungicide strategies for controlling gray mold diseases. Indeed, the application of siRNA and dsRNA targeting $B$. cinereal DCL1/2 genes on the surface of fruits and vegetables alleviates gray mold diseases [14]. The B. cinerea double mutant $d c l 1 d c l 2$ showed reduced virulence and disease progression in strawberry and tomato. However, the single mutant of the $d c l 1$ or $d c l 2$ showed similar disease progression as the wild-type strain [14]. Another study reported that oilseed rape infection by $B$. cinerea was mitigated by topical applications of the dsRNAs that target B. cinerea genes, including thioredoxin reductase, mitochondrial import inner membrane translocase subunit TIM44, peroxidase, pre-40S ribosomal particle, and necrosis- and ethylene-inducing peptide 2 [19]; on the other hand, dsRNAs targeting thioredoxin reductase and mitochondrial import inner membrane translocase subunit TIM44 showed fewer necrotic lesions.

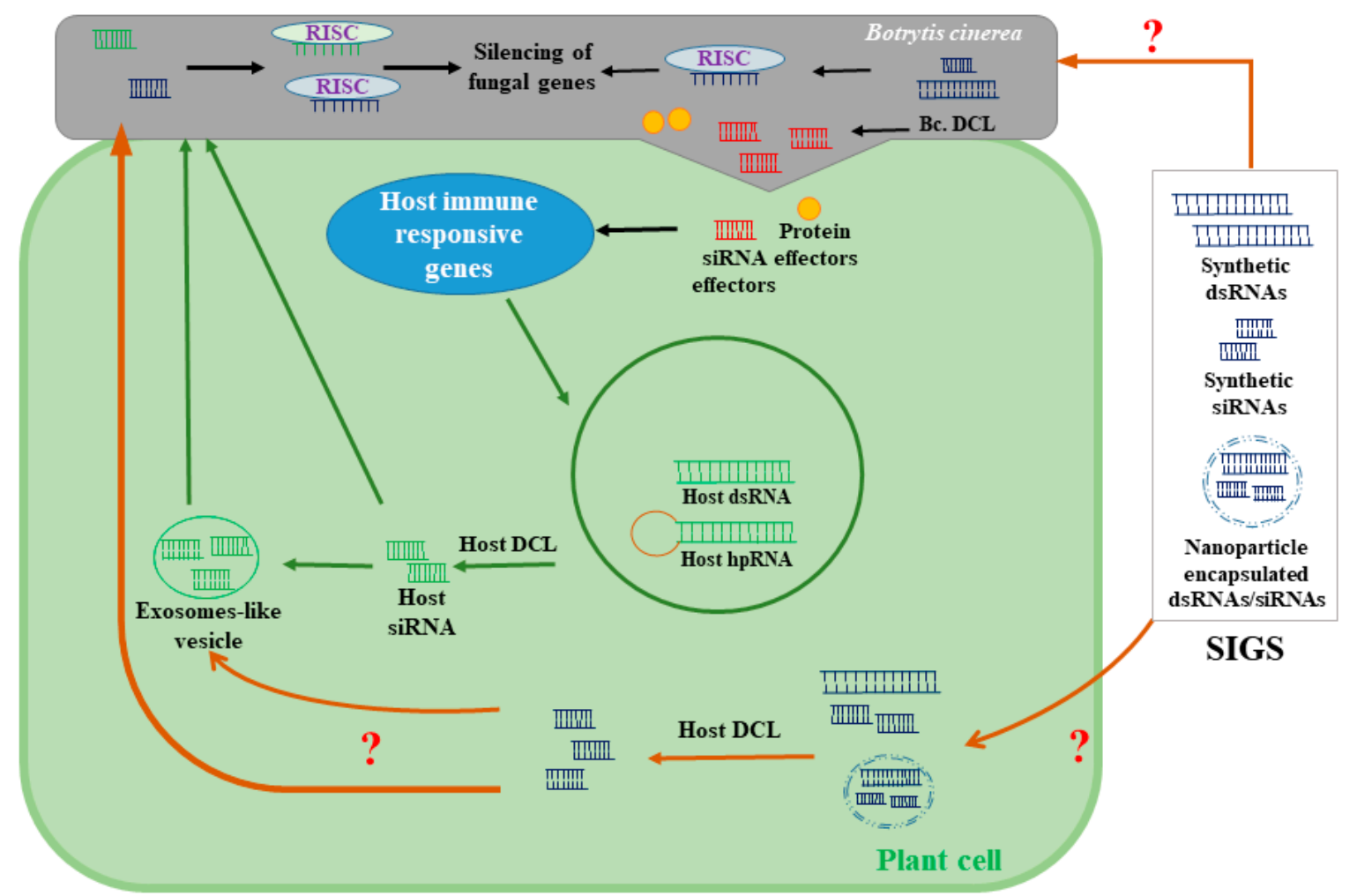

Figure 3. A model depicting possible mechanisms of spray-induced gene silencing (SIGS). SIGS using the exogenous applications of dsRNA or siRNA alleviates gray mold infections by targeting essential genes for B. cinerea virulence and pathogenicity. The mechanisms by which fungal cells uptake small RNA molecules are still unknown. It has also been proposed that sprayable forms of small RNA could be also transported to fungal cells through host cells. Although the uptake of exogenously applied siRNA and dsRNA by plant cells has already been shown, the mechanisms by which plants perceive and process exogenous RNA have not been identified. hpRNA: hairpin (hp) RNA; RISC: RNA-induced silencing complexes.

The virulence genes of the $B$. cinerea are a possible target for the RNAi-based fungicides, and this has been reviewed previously by Choquer et al. [53]. For instance, mutations in the $B$. cinerea chitin synthase genes (Bcchs3a) [54] or the genes involved in signal transduction including G $\alpha$ subunits of G-proteins ( $B c g 1, B c g 2$, and $B c g 3)[55,56]$ reduce the virulence of $B$. cinerea in different plant species. 
However, more detailed transcriptomic analyses are still required to identify effective SIGS targets at different stages of B. cinerea-host interactions. Unlike HIGS, SIGS does not involve stable genetic transformation [16], making it a more acceptable alternative to the genetically modified organisms that require approval from various regulatory agencies. In addition, an SIGS-based disease management approach is considered a feasible option for combating fungicide-resistant $B$. cinerea strains. Indeed, dsRNA can be used to silence the regions of $B$. cinerea genes that are essential for fungicide resistance, rendering the existing fungicides more effective. Topical applications of dsRNA and siRNA are obstructed by issues associated with the stability of these molecules under open-field conditions where temperature, humidity, and consistent exposure to UV could considerably affect their stability. Typically, the efficacy of naked RNA molecules can only persist for a few days [57]. However, plants sprayed with dsRNA loaded onto nanoparticles (e.g., BioClay) have shown a greater degree of protection against pathogenic infections for 30 days after application, both on treated and newly emerged leaves [58]. Nanoparticles have also been reported to improve the uptake of the dsRNA by root tips and the silencing of the target genes [59]. To enhance the efficacy and stability of SIGS-based RNA biofungicides, the sustained release of RNA fungicides using nanoparticles as a carrier or stabilizer would be beneficial.

\section{Conclusions and Future Perspectives}

Currently, chemical fungicides are still the most common disease management strategy against invading fungal diseases. In the past few years, HIGS has emerged as a promising management strategy against pests, nematodes, and fungal pathogens in different crop species [60-62]. However, HIGS depends mainly on the genetic modification of host plants, and their applicability to horticultural crops remains controversial, not necessarily due to technical limitations, but mainly because of consumer concerns with transgenic crops. SIGS, on the other hand, does not require a stable genetic transformation of host species, predicting that their approval via the regulatory agencies would likely go through a fast track and their public acceptance would not be as concerning. SIGS could be efficiently used for the pre- and post-harvest management of gray mold diseases in major horticultural crops such as tomatoes, strawberries, and grapes. However, target genes for RNAi-based fungicides are still limited, thus the detailed transcriptomic analyses are warranted to identify target genes for biotrophic and necrotrophic phases of $B$. cinerea infections. Moreover, the uptake mechanisms of exogenous dsRNA by plants or fungal cells remain inexplicable. The clear understanding of the roles of membrane-bound proteins and receptors of plant and fungal cells may improve our understanding of the underlying small RNA uptake mechanisms. The stability of naked dsRNA molecules under field conditions is another major concern that may limit the application of SIGS-based disease management strategies. However, the utilization of nanoparticles and other stabilizers for enhanced stability and sustained release of the RNAi-biofungicides could overcome these limitations. The development of cost-effective and scalable approaches for the production of RNAi-biofungicides is probably the major challenge facing the practical agricultural utilization of this technology. However, technologies such as the bacterially expressed small RNA (dsRNA, and hpRNA) and minicells could solve these issues in the future. To conclude, RNAi-based biofungicides hold a great potential for managing the devastating gray mold diseases; however, future studies should focus on formulation, synthesis, stability, and application methods for the sustained release of RNAi-based fungicides, to make SIGS more effective, applicable, and cost-effective and to facilitate the implementation of SIGS under open-field conditions.

Author Contributions: M.T.I. and S.M.S. have contributed to the writing, editing, and preparation of this review article. All authors have read and agreed to the published version of the manuscript.

Funding: The authors are grateful for the funding to SS from The Virginia Catalyst (Fund \# 460380).

Conflicts of Interest: The authors declare that no conflict of interest exists regarding the completion and publication of this research. 


\section{References}

1. Petrasch, S.; Knapp, S.J.; van Kan, J.A.L.; Blanco-Ulate, B. Grey mould of strawberry, a devastating disease caused by the ubiquitous necrotrophic fungal pathogen Botrytis cinerea. Mol. Plant Pathol. 2019, 20, 877-892. [CrossRef] [PubMed]

2. Dean, R.; van Kan, J.A.; Pretorius, Z.A.; Hammond-Kosack, K.E.; Di Pietro, A.; Spanu, P.D.; Rudd, J.J.; Dickman, M.; Kahmann, R.; Ellis, J.; et al. The Top 10 fungal pathogens in molecular plant pathology. Mol. Plant Pathol. 2012, 13, 414-430. [CrossRef] [PubMed]

3. Weiberg, A.; Wang, M.; Lin, F.M.; Zhao, H.; Zhang, Z.; Kaloshian, I.; Huang, H.D.; Jin, H. Fungal small RNAs suppress plant immunity by hijacking host RNA interference pathways. Science 2013, 342, 118-123. [CrossRef] [PubMed]

4. Veloso, J.; van Kan, J.A.L. Many shades of grey in Botrytis-host plant interactions. Trends Plant Sci. 2018, 23, 613-622. [CrossRef]

5. Pedras, M.S.; Hossain, S.; Snitynsky, R.B. Detoxification of cruciferous phytoalexins in Botrytis cinerea: Spontaneous dimerization of a camalexin metabolite. Phytochemistry 2011, 72, 199-206. [CrossRef]

6. Villa-Rojas, R.; Sosa-Morales, M.E.; Lopez-Malo, A.; Tang, J. Thermal inactivation of Botrytis cinerea conidia in synthetic medium and strawberry puree. Int. J. Food Microbiol. 2012, 155, 269-272. [CrossRef]

7. Malhat, F.M.; Haggag, M.N.; Loutfy, N.M.; Osman, M.A.; Ahmed, M.T. Residues of organochlorine and synthetic pyrethroid pesticides in honey, an indicator of ambient environment, a pilot study. Chemosphere 2015, 120, 457-461. [CrossRef]

8. Oliveira, B.R.; Penetra, A.; Cardoso, V.V.; Benoliel, M.J.; Barreto Crespo, M.T.; Samson, R.A.; Pereira, V.J. Biodegradation of pesticides using fungi species found in the aquatic environment. Environ. Sci. Pollut. R. 2015, 22, 11781-11791. [CrossRef]

9. Tomenson, J.A.; Matthews, G.A. Causes and types of health effects during the use of crop protection chemicals: Data from a survey of over 6300 smallholder applicators in 24 different countries. Int. Arch. Occup. Environ. Health 2009, 82, 935-949. [CrossRef]

10. Rupp, S.; Weber, R.W.S.; Rieger, D.; Detzel, P.; Hahn, M. Spread of Botrytis cinerea strains with multiple fungicide resistance in german horticulture. Front. Microbiol. 2017, 7, 2075. [CrossRef]

11. Fernández-Ortuño, D.; Grabke, A.; Li, X.; Schnabel, G. Independent emergence of resistance to seven chemical classes of fungicides in Botrytis cinerea. Phytopathology 2015, 105, 424-432. [CrossRef] [PubMed]

12. Qi, T.; Guo, J.; Peng, H.; Liu, P.; Kang, Z.; Guo, J. Host-induced gene silencing: A powerful strategy to control diseases of wheat and barley. Int. J. Mol. Sci. 2019, 20, 206. [CrossRef] [PubMed]

13. Wang, M.; Thomas, N.; Jin, H. Cross-kingdom RNA trafficking and environmental RNAi for powerful innovative pre- and post-harvest plant protection. Curr. Opin. Plant Biol. 2017, 38, 133-141. [CrossRef] [PubMed]

14. Wang, M.; Weiberg, A.; Lin, F.M.; Thomma, B.P.H.J.; Huang, H.D.; Jin, H. Bidirectional cross-kingdom RNAi and fungal uptake of external RNAs confer plant protection. Nat. Plants 2016, 2, 16151. [CrossRef]

15. Xiong, F.; Liu, M.; Zhuo, F.; Yin, H.; Deng, K.; Feng, S.; Liu, Y.; Luo, X.; Feng, L.; Zhang, S.; et al. Host-induced gene silencing of BcTOR in Botrytis cinerea enhances plant resistance to grey mould. Mol. Plant Pathol. 2019, 20, 1722-1739. [CrossRef] [PubMed]

16. Machado, A.K.; Brown, N.A.; Urban, M.; Kanyuka, K.; Hammond-Kosack, K.E. RNAi as an emerging approach to control Fusarium head blight disease and mycotoxin contamination in cereals. Pest Manag. Sci. 2018, 74, 790-799. [CrossRef]

17. Koch, A.; Biedenkopf, D.; Furch, A.; Weber, L.; Rossbach, O.; Abdellatef, E.; Linicus, L.; Johannsmeier, J.; Jelonek, L.; Goesmann, A.; et al. An RNAi-based control of Fusarium graminearum infections through spraying of long dsRNAs involves a plant passage and is controlled by the fungal silencing machinery. PLoS Pathog. 2016, 12, e1005901. [CrossRef]

18. Song, X.S.; Gu, K.X.; Duan, X.X.; Xiao, X.M.; Hou, Y.P.; Duan, Y.B.; Wang, J.X.; Yu, N.; Zhou, M.G. Secondary amplification of siRNA machinery limits the application of spray-induced gene silencing. Mol. Plant Pathol. 2018, 19, 2543-2560. [CrossRef]

19. Mcloughlin, A.G.; Wytinck, N.; Walker, P.L.; Girard, I.J.; Rashid, K.Y.; De Kievit, T.; Fernando, W.G.D.; Whyard, S.; Belmonte, M.F. Identification and application of exogenous dsRNA confers plant protection against Sclerotinia sclerotiorum and Botrytis cinerea. Sci. Rep. 2018, 8, 7320. [CrossRef] 
20. Mcloughlin, A.G.; Walker, P.L.; Wytinck, N.; Sullivan, D.S.; Whyard, S.; Belmonte, M.F. Developing new RNA interference technologies to control fungal pathogens. Can. J. Plant Pathol. 2018, 40, 325-335. [CrossRef]

21. Kandasamy, S.K.; Fukunaga, R. Phosphate-binding pocket in Dicer-2 PAZ domain for high-fidelity siRNA production. Proc. Natl. Acad. Sci. USA 2016, 113, 14031-14036. [CrossRef] [PubMed]

22. Dang, Y.; Yang, Q.; Xue, Z.; Liu, Y. RNA interference in fungi: Pathways, functions, and applications. Eukaryot. Cell 2011, 10, 1148-1155. [CrossRef] [PubMed]

23. Voinnet, O. Origin, biogenesis, and activity of plant microRNAs. Cell 2009, 136, 669-687. [CrossRef] [PubMed]

24. Dalakouras, A.; Wassenegger, M.; Dadami, E.; Ganopoulos, I.; Pappas, M.L.; Papadopoulou, K. Genetically modified organism-free RNA interference: Exogenous application of RNA molecules in plants. Plant Physiol. 2020, 182, 38-50. [CrossRef] [PubMed]

25. Chan, S.W.; Zilberman, D.; Xie, Z.; Johansen, L.K.; Carrington, J.C.; Jacobsen, S.E. RNA silencing genes control de novo DNA methylation. Science 2004, 303, 1336. [CrossRef]

26. Weiberg, A.; Jin, H. Small RNAs-The secret agents in the plant-pathogen interactions. Curr. Opin. Plant Biol. 2015, 26, 87-94. [CrossRef]

27. Mandadi, K.K.; Karen-Beth, G.; Scholthof, K.B.G. Plant immune responses against viruses: How does a virus cause disease? Plant Cell 2013, 25, 1489-1505. [CrossRef]

28. Zhang, X.; Dai, Y.; Xiong, Y.; DeFraia, C.; Li, J.; Dong, X.; Mou, Z. Overexpression of Arabidopsis MAP kinase kinase leads to activation of plant basal and systemic acquired resistance. Plant J. 2007, 52, 1066-1079. [CrossRef]

29. Lang, J.; Genot, B.; Hirt, H.; Colcombet, J. Constitutive activity of the Arabidopsis MAP Kinase 3 confers resistance to Pseudomonas syringae and drives robust immune responses. Plant Signal. Behav. 2017, 12, e1356533. [CrossRef]

30. Genenncher, B.; Wirthmueller, L.; Roth, C.; Klenke, M.; Ma, L.; Sharon, A.; Wiermer, M. Nucleoporin-regulated MAP kinase signaling in immunity to a necrotrophic fungal pathogen. Plant Physiol. 2016, 172, 1293-1305. [CrossRef]

31. Islam, M.T.; Lee, B.R.; Park, S.H.; La, V.H.; Bae, D.W.; Kim, T.H. Cultivar variation in hormonal balance is a significant determinant of disease susceptibility to Xanthomonas campestris pv. campestris in Brassica napus. Front. Plant Sci. 2017, 8, 2121. [CrossRef]

32. Finiti, I.; Leyva, M.O.; Vicedo, B.; Gómez-pastor, R.; López-cruz, J.; Garcíaagustín, P.; Real, M.D.; González-Boschet, C. Hexanoic acid protects tomato plants against Botrytis cinerea by priming defense responses and reducing oxidative stress. Mol. Plant Pathol. 2014, 15, 550-562. [CrossRef]

33. van Kan, J.A.L. Licensed to kill: The lifestyle of a necrotrophic plant pathogen. Trends. Plant Sci. 2006, 11, 247-253. [CrossRef]

34. Brutus, A.; Sicilia, F.; Macone, A.; Cervone, F.; De Lorenzo, G. A domain swap approach reveals a role of the plant wall-associated kinase 1 (WAK1) as a receptor of oligogalacturonides. Proc. Natl. Acad. Sci. USA 2010, 107, 9452-9457. [CrossRef]

35. Ferrari, S.; Savatin, D.V.; Sicilia, F.; Gramegna, G.; Cervone, F.; De Lorenzo, G. Oligogalacturonides: Plant damage-associated molecular patterns and regulators of growth and development. Front. Plant Sci. 2013, 4, 49. [CrossRef]

36. Wang, M.; Weiberg, A.; Dellota, E.; Yamane, D.; Jin, H. Botrytis small RNA Bc-siR37 suppresses plant defense genes by cross-kingdom RNAi. RNA Biol. 2017, 14, 421-428. [CrossRef]

37. Kim, K.C.; Fan, B.; Chen, Z. Pathogen-induced Arabidopsis WRKY7 is a transcriptional repressor and enhances plant susceptibility to Pseudomonas syringae. Plant Physiol. 2006, 142, 1180-1192. [CrossRef]

38. Jiang, Y.; Liang, G.; Yang, S.; Yu, D. Arabidopsis WRKY57 functions as a node of convergence for jasmonic acidand auxin-mediated signaling in jasmonic acid-induced leaf senescence. Plant Cell. 2014, 26, 230-245. [CrossRef]

39. Staiger, D.; Korneli, C.; Lummer, M.; Navarro, L. Emerging role for RNA-based regulation in plant immunity. New Phytol. 2013, 197, 394-404. [CrossRef]

40. Lopez, A.; Ramirez, V.; Garcia-Andrade, J.; Flors, V.; Vera, P. The RNA silencing enzyme RNA polymerase v is required for plant immunity. PLoS Genet. 2011, 7, e1002434. [CrossRef]

41. Cai, Q.; Qiao, L.; Wang, M.; He, B.; Lin, F.M.; Palmquist, J.; Huang, S.D.; Jin, H. Plants send small RNAs in extracellular vesicles to fungal pathogen to silence virulence genes. Science 2018, 360, 1126-1129. [CrossRef]

42. Jeong, B.R.; Lin, Y.; Joe, A.; Guo, M.; Korneli, C.; Yang, H.; Wang, P.; Yu, M.; Cerny, R.L.; Staiger, D.; et al. Structure function analysis of an ADP ribosyltransferase type III effector and its RNA-binding target in plant immunity. J. Biol. Chem. 2011, 286, 43272-43281. [CrossRef] 
43. Islam, M.T.; Lee, B.R.; Park, S.H.; La, V.H.; Jung, W.J.; Bae, D.W.; Kim, T.H. Hormonal regulations in soluble and cell-wall bound phenolics accumulation in two cultivars of Brassica napus contrasting susceptibility to Xanthomonas campestris pv. campestris. Plant Sci. 2019, 285, 132-140. [CrossRef]

44. Saito, S.; Michailides, T.J.; Xiao, C.L. Fungicide resistance profiling in Botrytis cinerea populations from blueberry in California and Washington and their impact on control of gray mold. Plant Dis. 2016, 100, 2087-2093. [CrossRef]

45. Veloukas, T.; Kalogeropoulou, P.; Markoglou, A.N.; Karaoglanidis, G.S. Fitness and competitive ability of Botrytis cinerea field-isolates with dual resistance to SDHI and QoI fungicides, associated with several $s d h \mathrm{~B}$ and the cytb G134A mutations. Phytopathology 2014, 104, 347-356. [CrossRef]

46. Dias, M.C. Phytotoxicity: An overview of the physiological responses of plants exposed to fungicides. J. Bot. 2012, 2012, 135479. [CrossRef]

47. Vuković, S.; Inđić, D.; Gvozdenac, S. Phytotoxic effects of fungicides, insecticides and nonpesticidal components on pepper depending on water quality. Pestic. Phytomed. 2014, 29, 145-153.

48. Gupta, P.K. Toxicity of fungicides. In Veterinary Toxicology, 3rd ed.; Gupta, R.C., Ed.; Academic Press: Cambridge, MA, USA, 2018; pp. 569-580.

49. Amiri, A.; Heath, S.M.; Peres, N.A. Phenotypic characterization of multifungicide resistance in Botrytis cinerea isolates from strawberry fields in Florida. Plant Dis. 2013, 97, 393-401. [CrossRef]

50. Weber, R.W.S. Resistance of Botrytis cinerea to multiple fungicides in Northern German small-fruit production. Plant Dis. 2011, 95, 1263-1269. [CrossRef]

51. Panebianco, A.; Castello, I.; Cirvilleri, G.; Perrone, G.; Epifani, F.; Ferrara, M.; Polizzia, G.; Walters, D.R.; Vitale, A. Detection of Botrytis cinerea field isolates with multiple fungicide resistance from table grape in Sicily. Crop. Protect. 2015, 77, 65-73. [CrossRef]

52. Konstantinou, S.; Veloukas, T.; Leroch, M.; Menexes, G.; Hahn, M.; Karaoglanidis, G. Population structure, fungicide resistance profile, and $\mathrm{sdhB}$ mutation frequency of Botrytis cinerea from strawberry and greenhouse-grown tomato in Greece. Plant Dis. 2015, 99, 240-248. [CrossRef]

53. Choquer, M.; Fournier, E.; Kunz, C.; Levis, C.; Pradier, J.M.; Simon, A.; Viaud, M. Botrytis cinerea virulence factors: New insights into a necrotrophic and polyphageous pathogen. FEMS Microbiol. Lett. 2007, 277, 1-10. [CrossRef]

54. Soulie, M.C.; Perino, C.; Piffeteau, A.; Choquer, M.; Malfatti, P.; Cimerman, A.; Kunz, C.; Boccara, M.; Anne Vidal-Croset, A. Botrytis cinerea virulence is drastically reduced after disruption of chitin synthase class III gene (Bcchs3a). Cell Microbiol. 2006, 8, 1310-1321. [CrossRef]

55. Schulze Gronover, C.S.; Kasulke, D.; Tudzynski, P.; Tudzynski, B. The role of G protein alpha subunits in the infection process of the gray mold fungus Botrytis cinerea. Mol. Plant Microbe Interact. 2001, 14, 1293-1302. [CrossRef]

56. Doehlemann, G.; Berndt, P.; Hahn, M. Different signaling pathways involving a Galpha protein, cAMP and a MAP kinase control germination of Botrytis cinerea conidia. Mol. Microbiol. 2006, 59, 821-835. [CrossRef]

57. Dubrovina, A.S.; Kiselev, K.V. Exogenous RNAs for gene regulation and plant resistance. Int. J. Mol. Sci. 2019, 20, 2282. [CrossRef]

58. Mitter, N.; Worrall, E.A.; Robinson, K.E.; Li, P.; Jain, R.G.; Taochy, C.; Fletcher, S.J.; Carroll, B.J.; Lu, G.Q.; $\mathrm{Xu}$, Z.P. Clay nanosheets for topical delivery of RNAi for sustained protection against plant viruses. Nat. Plants 2017, 3, 16207. [CrossRef]

59. Worrall, E.A.; Hamid, A.; Mody, K.T.; Mitter, N.; Pappu, H.R. Nanotechnology for plant disease management. Agronomy 2018, 8, 285. [CrossRef]

60. Huang, G.Z.; Allen, R.; Davis, E.L.; Baum, T.J.; Hussey, R.S. Engineering broad root-knot resistance in transgenic plants by RNAi silencing of a conserved and essential root-knot nematode parasitism gene. Proc. Natl. Acad. Sci. USA 2006, 103, 14302-14306. [CrossRef]

61. Nowara, D.; Gay, A.; Lacomme, C.; Shaw, J.; Ridout, C.; Douchkov, D.; Hensel, G.; Kumlehn, J.; Schweizeret, P. HIGS: Host-Induced gene silencing in the obligate biotrophic fungal pathogen Blumeria graminis. Plant Cell. 2010, 22, 3130-3141. [CrossRef]

62. Nunes, C.C.; Dean, R.A. Host-induced gene silencing: A tool for understanding fungal host interaction and for developing novel disease control strategies. Mol. Plant Pathol. 2012, 13, 519-529. [CrossRef]

(C) 2020 by the authors. Licensee MDPI, Basel, Switzerland. This article is an open access article distributed under the terms and conditions of the Creative Commons Attribution (CC BY) license (http://creativecommons.org/licenses/by/4.0/). 